\title{
The Effect of Promotional Mix on Pricebook Brand Awareness
}

\section{Faldhi Lazuardi, Satiri}

\section{INSTITUTION}

Program Studi Ilmu Komunikasi,

STIKom Interstudi,

Indonesia

\section{PHONE}

\section{EMAIL}

lazuardifaldhi@gmail.com satiri@iuli.ac.id

\section{DOI}

https://www.doi.org/

10.37010/prop.v2i1.584

\section{PAPER PAGE}

99-109

PROPAGANDA is a Journal of Communication Studies which is publish twice a year on January and July. PROPAGANDA is a scientific publication media in the form of conceptual paper and field research related to communication studies. It is hoped that PROPAGANDA can become a media for academics and researchers to publish their scientific work and become a reference source for the development of science and knowledge.

\author{
Pengaruh Bauran Promosi terhadap Kesadaran Merek \\ Pricebook
}

\begin{abstract}
Dalam komunikasi bisnis ada banyak strategi dalam promosi, salah satunya adalah bauran promosi. Tujuan penelitian ini adalah untuk mengetahui pengaruh bauran promosi (promotion mix) terhadap kesadaran merek (brand awareness) pada website, sosial media, serta channel YouTube Pricebook. Pricebook merupakan sebuah perusahaan start-up yang bergerak di bidang teknologi dan informasi. Pricebook menyampaikan informasi-informasi seputar ketersediaan produk, toko online maupun offline, yang dikemas dalam website secara unik dan praktis. Metode yang digunakan adalah dengan melakukan survei yang akan diberikan kepada objek pengunjung website serta viewers dan subscriber YouTube Pricebook yang akan diteliti. Rancangan penelitian ini memiliki tujuan untuk mencari pengaruh antar dua variabel yaitu variabel (X) adalah bauran promosi (promotion mix) sedangkan variabel (Y) adalah kesadaran merek (brand awareness). Responden yang dilibatkan dalam penelitian ini adalah pengunjung website dan viewers/subscriber YouTube Pricebook yang telah mengunjungi atau menonton Pricebook sebanyak 3 kali atau lebih sebanyak 97 orang. Teknik pengambilan sampel menggunakan non probability sampling dengan metode teknik sampel menggunakan purposive sampling. Hasil dari penelitian ini menunjukkan bauran promosi (promotion mix) yang terdiri dari periklanan dan hubungan masyarakat memiliki pengaruh yang signifikan dengan 0,739>0,05, korelasi yang kuat dengan nilai 0,686 dan berpengaruh positif sebanyak 47\% terhadap kesadaran merek (brand awareness) yang didukung oleh hasil survei dan perhitungan secara statistik menggunakan software SPSS, dengan kata lain sebagian kesadaran merek (brand awareness) Pricebook dipengaruhi oleh bauran promosi (promotion mix).
\end{abstract}

In business communication there are many strategies in promotion, one of which is the promotion mix. The purpose of this study was to determine the effect of the Promotion Mix on Brand Awareness on websites, social media, and Pricebook's YouTube channel. Pricebook is a startup company engaged in technology and information. Pricebook conveys information about product availability, online and offline stores, which are packaged in a unique and practical website. The method used is to conduct a survey that will be given to the object of website visitors as well as viewers and subscribers of Pricebook YouTube that will be studied. This research design aims to find the effect between two variables, namely Variable $(X)$ is the Promotion Mix, while the variable ( $Y$ ) is Brand Awareness. Respondents involved in this study were website visitors and Pricebook YouTube viewers/subscribers who had visited or watched Pricebook 3 times or more as many as 97 people. The sampling technique used non-probability sampling with the sampling technique method using purposive sampling. The results of this study indicate the Promotion Mix which consists of Advertising and Public Relations has a significant effect with $0.739>0.05$, a strong correlation with a value of 0.686 and a positive effect of $47 \%$ on Brand Awareness which is supported by survey results and statistical calculations using SPSS software, in other words some of Pricebook's Brand Awareness is influenced by the Promotion Mix.

\section{KEYWORD}

promotional mix, brand awareness, advertising, public relations

bauran promosi, kesadaran merek, periklanan, hubungan masyarakat 


\section{PROPAGANDA}

\section{PENDAHULUAN}

Dalam proses penjualan suatu produk, baik berupa barang atau jasa, pasti ada kegiatan pemasaran di dalamnya. Kotler dan Armstrong (Armstrong, 2014, p. 27) menyatakan pemasaran dapat dikatakan sebagai proses untuk menciptakan nilai-nilai untuk pelanggan dan menjaga hubungan baik antara pelanggan dengan perusahaan dengan harapan atau tujuan untuk mendapatkan feedback. Kegiatan marketing atau pemasaran memerlukan strategi pemasaran dalam melancarkan suatu produk dalam mencapai tujuannya yaitu penjualan. Menurut Tjiptono (2015) "Strategi pemasaran adalah alat yang berfungsi untuk membantu perusahaan mencapai tujuan dengan melakukan pengembangan keunggulan yang saling berkesinambungan dalam bersaing dengan pasar yang dituju dan program pemasaran untuk melayani pasar tersebut". Strategi Pemasaran banyak macamnya, salah satunya adalah promotion mix. Promotion mix adalah turunan dari marketing mix yang lebih memfokuskan strategi pada kegiatan promosi. Menurut Swastha \& Irawan (2016: 349) Bauran promosi (promotion mix) adalah kombinasi strategi pemasaran yang mencakup variabel-variabel promosi seperti advertising, personal selling, direct marketing, public relations, dan sales promotion yang direncanakan untuk mencapai tujuan program penjualan perusahaan.

Saat ini perusahaan yang bergerak di bidang teknologi makin banyak bermunculan di Indonesia. Salah satu jenis perusahaan yang bergerak di bidang teknologi adalah start-up. Menurut Paul Graham (Siregar, 2020) mendefinisikan start-up sebagai perusahaan yang didesain untuk tumbuh dengan cepat. Salah satu perusahaan start-up di Indonesia adalah Pricebook. Dikutip dari website Pricebook, perusahaan ini menjelaskan bahwa Pricebook merupakan sebuah perusahaan start-up yang bergerak di bidang teknologi dan informasi. Pricebook menyampaikan informasi-informasi seputar ketersediaan produk, toko online maupun offline, yang dikemas dalam website secara unik dan praktis. Pricebook menggunakan situs web dan media sosial sebagai sarana membagikan informasi yang membantu jutaan orang mempertimbangkan keputusan belanja setiap bulannya. Pricebook membantu penggunanya untuk membandingkan harga, cek lokasi dan pengiriman, dan cek metode pembayaran produk yang akan dibeli pengguna. Pricebook juga dapat membantu dengan memberikan informasi harga terendah produk- produk elektronik yang diinginkan dari berbagai toko online maupun offline. Saat ini, channel YouTube Pricebook telah memiliki 1.080 .000 subscriber. Pada channel ini terdapat banyak konten seperti unboxing dan review gadget, marzoom (market zoom), extreme test, dan masih banyak lagi. Pada website Pricebook, kini telah menyediakan lebih banyak informasi tidak hanya gadget melainkan seperti otomotif, elektronik lain seperti TV dan lain-lain, serta make-up (beauty). Rata-rata viewers video popular Pricebook berkisar antara ratusan ribu hingga jutaan. Video dengan viewers terbanyak telah mencapai 2.6 juta kali ditonton. Pricebook juga memiliki banyak official partners seperti Tokopedia, Blibli.com, Bukalapak, Lazada, dan Bhinneka.

Dengan adanya perkembangan perusahaan start-up di Indonesia dan kemajuan teknologi yang mendukung kegiatan promosi dalam promotion mix, mendorong peneliti untuk melakukan penelitian promotion mix pada perusahaan start-up yaitu Pricebook. Masalah penelitiannya yaitu, untuk saat ini Pricebook cukup dikenal oleh penggiat gadget, namun untuk penonton awam, Pricebook masih kurang dikenal. Oleh karena itu peneliti berniat untuk melakukan penelitian yang ditujukan agar Pricebook dapat mengoptimalkan kegiatan promosinya untuk meningkatkan kesadaran merek bukan hanya pengingat gadget, namun penonton awam juga. Alasan peneliti memilih Pricebook sebagai objek dalam penelitian ini karena peneliti juga memiliki kerabat yang bekerja di Pricebook sebagai marketing communication manager. Dengan begitu diharapkan dapat memudahkan peneliti untuk memperoleh data-data yang dibutuhkan dalam penelitian ini. 
Penelitian ini bertujuan untuk mengetahui apakah ada pengaruh antara bauran promosi (promotion mix) dengan kesadaran merek (brand awareness) dan seberapa besar pengaruhnya. Memilih PT Pricebook sebagai tempat penelitian karena saat ini channel YouTube Pricebook yang bergerak di bidang teknologi/gadget berkembang pesat. Channel YouTube Pricebook saat ini memiliki 1,2 juta subscriber dengan viewer terbanyak pada videonya sekitar 3 juta views. Website Pricebook juga saat ini berkembang dengan fitur-fitur yang lebih banyak seperti forum, berita, komunitas gadget, dan masih banyak lagi.

Ada beberapa jurnal/penelitian terdahulu yang menjadi referensi penelitian ini. Pertama yaitu jurnal dengan judul Analisis Pengaruh Bauran Promosi Terhadap Kesadaran Merek (Brand Awareness) Tabungan Britama PT BRI (PERSERO) TBK. Kantor Cabang di Tebing Tinggi yang diteliti oleh Horja Raja Sitorus Pane (2011). Hasil penelitian pada hipotesis pertama menunjukkan bahwa periklanan, promosi penjualan, dan hubungan masyarakat secara simultan berpengaruh secara signifikan terhadap kesadaran merek. Secara parsial, promosi penjualan merupakan faktor yang paling berpengaruh terhadap kesadaran merek. Sedang hasil penelitian pada hipotesis kedua menunjukkan hadiah undian dan barang gratis secara simultan berpengaruh secara signifikan terhadap promosi penjualan.

Penelitian kedua berjudul Pengaruh Promotion Mix Terhadap Brand Awareness PT HM Sampoerna TBK Melalui Produk Terbaru Sampoerna A Platinum. Penelitian ini diteliti oleh Andreas Sulistio, Prof. Dr. Hatane Semuel S.E,. MM (2018). Setelah dilakukan penelitian, hasil yang diperoleh adalah semua kegiatan promosi dalam promotion mix yaitu periklanan, tanggung jawab sosial perusahaan, pemasaran langsung, promosi penjualan dan penjualan personal, berpengaruh baik pada kesadaran merek PT HM Sampoerna TBK. Perbedaan penelitian terdahulu di atas dengan penelitian yang sedang diteliti adalah objek penelitian dan responden yang ditelitinya. Serta produk penelitian terdahulu berupa barang, sedangkan produk pada penelitian yang sedang diteliti adalah jasa (Sulistio, 2018).

Bauran promosi (promotion mix) adalah kombinasi strategi pemasaran yang mencakup variabel-variabel promosi seperti advertising, personal selling, direct marketing, public relations, dan sales promotion yang direncanakan untuk mencapai tujuan program penjualan perusahaan (Swastha; Irawan, 2016). Menurut Kotler dan Armstrong (Kotler, 2012, p. 600) kegiatan promosi pada bauran promosi ada lima yaitu:

a. Periklanan (advertising) menurut Wells, Burnett dan Moriarty (2012) iklan adalah "suatu bentuk komunikasi non-personal yang dilakukan oleh perusahaan dengan mengeluarkan biaya dalam penggunaan media massa dengan tujuan untuk membujuk dan mempengaruhi audiens". Tujuan periklanan menurut Shimp (2014: 357) iklan dapat memberikan informasi produk baru dan memicu kesadaran merk terhadap calon konsumen (brand awareness). Iklan juga dapat menarik konsumen untuk melakukan pembelian (persuading). Iklan juga dapat mengingatkan konsumen tentang produk dan perusahaan (reminding).

b. Sales promotion (promosi penjualan), menurut Lupiyoadi (2013: 180) "Promosi penjualan merupakan segala kegiatan yang bertujuan untuk meningkatkan arus produk baik itu barang atau jasa dari produsen sampai pada penjualan akhir. Pada promosi penjualan terdiri atas beberapa titik yaitu brosur, lembar informasi, dan lain-lain". Menurut Kotler dan Armstrong dalam buku Prinsip- prinsip Pemasaran (Armstrong, 2014: 174) tujuan dari sales promotion sangat bervariasi. Pertama, penjual dapat menggunakan sales promotion untuk meningkatkan penjualan jangka pendek maupun jangka panjang. Kedua, membantu pengecer untuk menjual produk baru dan memberikan ruang lebih banyak untuk persediaan. Ketiga, sales promotion dapat memberikan dukungan pada penjualan produk baru dan mencari pelanggan baru.

c. Public relations (hubungan masyarakat) Menurut Cutlip, Center \& Broom (2010: 25) "Public relations berfungsi sebagai alat manajemen yang dilakukan oleh organisasi yang 


\section{PROPAGANDA}

ditujukan kepada publik untuk membangun dan mempertahankan hubungan harmonis dengan publik". Menurut (Ardianto; Soemirat, 2012, p. 89) PR bertujuan untuk memberikan pengertian dan goodwill agar dapat memperoleh feedback dari publik sebagai keuntungan untuk membangun hubungan baik agar tercipta kerja sama.

d. Personal selling (penjualan perorangan). Menurut Johnson, dkk. (2017: 5) "Penjualan personal adalah aspek paling krusial menurut taktik penjualan perusahaan. Kapan saat yang tepat untuk digunakan \& berhasil dengan baik, faktor utama dalam volume penjualan ini adalah bagian dari promosi yang membawa unsur manusia kepada transaksi pemasaran". Menurut Shimp (2014: 281), personal selling bertujuan untuk menyampaikan informasi kepada pelanggan, penyediaan produk yang berfungsi untuk membantu pemasaran, serta membantu layanan jual dan mendukung pembeli

e. Direct marketing (pemasaran langsung). Menurut Saladin (Djasmin, 2012: 191) memerlukan proses komunikasi untuk mampu berada pada posisi puncak dalam tingkatan brand awareness (Sasmita \& Suki, 2015). Dan juga, brand awareness berdampak secara signifikan terhadap pengambilan keputusan pihak konsumen yang menguntungkan pengelolaan ekuitas merek berbasis pelanggan (Sasmita \& Suki, 2015).

Menurut Aaker (dalam Durianto, Darmadi; Sugiarto; Sitinjak, 2011) brand awareness dapat diukur dalam beberapa tingkatan, yaitu top of mind atau bisa disebut puncak pikiran, pengingat kembali merek atau disebut brand. "Pemasaran langsung berfungsi sebagai suatu sistem pemasaran dengan menggunakan iklan atau recall, pengenalan merek atau disebut brand recognition dan tidak menyadari adanya merek atau disebut Unaware of Brand. berbagai media lain untuk mendapatkan feedback atau transaksi yang dituju oleh perusahaan". Menurut Kotler dan Armstrong (2014: 221) direct marketing bertujuan agar terciptanya hubungan baik antara konsumen dan perusahaan serta untuk mendapatkan feedback yang menguntungkan perusahaan.

Brand awareness adalah bagaimana konsumen mengasosiasikan atau menghubungkan sebuah merek dengan produk tertentu yang diinginkan oleh konsumen. Brand awareness memiliki beberapa tingkatan yaitu;

a. Top of Mind atau puncak pikiran

Saat yang bersangkutan ditanya suatu produk, maka gambaran merek yang pertama diingat atau disebut itu adalah yang ada di puncak pikiran mereka.

b. Pengingatan kembali terhadap merek (Brand Recall) Saat responden mengingat dan menyebutkan merek yang pertama kali mereka sebut, itu adalah bentuk brand recall.

c. Pengenalan merek atau Brand Recognition

Setelah mengingat kembali merek dengan bantuan, maka itu adalah bentuk pengenalan suatu merek dengan tingkat kesadaran minimal.

d. Unaware of Brand atau tidak menyadari merek

Pada tingkat ini, konsumen tidak mengetahui atau menyadari adanya suatu merek sama sekali

Durianto (2011), mengatakan tingkat awareness atau kesadaran pembeli/konsumen suatu merek bisa ditingkatkan dengan beberapa cara/upaya sebagai berikut:

a. Mengungkapkan pesan yang mudah diingat adalah salah satu kewajiban dari suatu merek untuk para konsumen. Pesan yang diungkapkan juga harus berhubungan dengan merek dan kategori produknya.

b. Jingle lagu atau jargon dapat menjadi strategi perusahaan untuk menarik konsumen agar merek lebih mudah diingat.

c. Perusahaan disarankan untuk memiliki simbol yang berhubungan dengan merek.

d. Merek dapat digunakan oleh perusahaan untuk memperluas jangkauan produk dengan tujuan agar merek dapat lebih diingat oleh konsumen. 
e. Memperkuat kesadaran merek dapat dilakukan melalui suatu isyarat yang cocok digunakan pada produk dan merek perusahaan.

f. Perusahaan harus melakukan pengulangan untuk meningkatkan ingatan pada pikiran konsumen terhadap merek. Karena membentuk ingatan akan lebih sulit daripada memperkenalkan barang/produk baru.

Pada kegiatan promosi advertising, hampir seluruh kegiatannya menggunakan komunikasi non personal. Hal ini dikarenakan advertising selalu menggunakan media baik itu cetak maupun elektronik. Dengan menggunakan komunikasi non personal yaitu media (cetak/elektronik), advertising dapat sangat mempengaruhi brand awareness karena dari iklan, kesadaran merek dapat meningkat tanpa harus bertatap muka langsung atau kontak langsung dengan calon konsumen. Dalam kegiatan promosi direct marketing dan sales promotion, komunikasi non personal juga kerap digunakan. Media seperti brosur, iklan, dan lain-lain juga digunakan untuk meningkatkan brand awareness. Pada kegiatan promosi lainnya public relations dan personal selling, umumnya menggunakan komunikasi personal untuk implementasinya. Kegiatan promosi yang menggunakan komunikasi personal juga sangat berpengaruh dalam meningkatkan brand awareness.

Penggunaan bauran promosi merupakan salah satu kewajiban perusahaan yang harus diperhatikan. Hal ini dikarenakan bauran promosi merupakan pertimbangan konsumen saat akan membeli produk di mana kegiatan-kegiatan promosi ditujukan untuk memperkenalkan produk kepada konsumen.

Menurut Alma dalam bukunya, bauran promosi merupakan asalah satu bentuk dari komunikasi pemasaran yang berfungsi sebagai alat untuk mengembangkan informasi, a memberikan pengaruh dan meningkatkan target pasar perusahaan \& produk supaya diterima oleh pembeli dan pelanggan loyal pada produk yang ditawarkan perusahaan (Buchari, 2014. P. 179)

\section{METODE}

Penelitian ini dilakukan melalui pendekatan kuantitatif. Jenis penelitian ini adalah eksplanatif. Penelitian ini menggunakan non probability sampling sebagai teknik pengambilan sampel dan purposive sampling sebagai metode teknik sampel. Menurut Sugiyono, purposive samplingabcd merupakan teknik penentuan sampel dengan pertimbangan tertentu (Sugiyono, 2017, p. 68).

Dalam penelitian ini banyak sampel yang akan adalah 97 responden. 97 responden tersebut diperoleh dari banyak sampel yang akan mewakili populasi yang akan diteliti yang bersifat tidak terbatas (infinite) (Umar, 2011: 150), dihitung dengan menggunakan rumus sebagai berikut:

$$
\mathrm{n}=\frac{\mathrm{Z}^{2} \cdot p \cdot q}{d 2}
$$

Keterangan :

$\mathrm{n} \quad=$ Jumlah sampel

$\mathrm{Z} \quad=$ Harga standar normal $(1,967)$

$\mathrm{P} \quad=$ Estimator proporsi normal $(0,5)$

$\mathrm{D} \quad=$ Interval penyimpangan $(0,10)$

$\mathrm{Q} \quad=1-\mathrm{p} \quad$ (proporsi yang diinginkan memiliki karakteristik tertentu)

Maka besar jumlah sampel dapat dihitung sebagai berikut:

$(1,967)^{2}(0,5)(0,5)$ 


\section{PROPAGANDA}

$\mathrm{n}=$

$(0,1)^{2}$

$\mathrm{n}=97$ responden

Hasil dari data ini sendiri akan diolah dan diuji sedemikian rupa dengan menggunakan software SPSS.

Ciri-ciri responden survei ini adalah sebagai berikut:

Usia 18-35 tahun

Diambil dari data statistik pengunjung website dan penonton YouTube Pricebook, audience paling banyak ada di usia 18-35 tahun.

- Telah mengunjungi website atau menonton channel YouTube Pricebook minimal 3 kali.

\section{Hipotesis Penelitian}

Hipotesis penelitian menurut (Sugiyono, 2017) adalah jawaban sementara dari rumusan masalah penelitian yang dinyatakan dalam bentuk kalimat pernyataan. Maka hipotesis penelitan pada penulisan ini adalah:

H0: $\quad$ Tidak Terdapatnya Pengaruh yang Signifikan Antara Pengaruh Promotion Mix Terhadap Brand Awareness Pricebook.

H1: Terdapatnya Pengaruh yang Signifikan Antara Pengaruh Promotion Mix Terhadap Brand Awareness Pricebook.

\section{Hipotesis Statistik}

Hipotesis statistik merupakan penjelasan tentang keadaan populasi yang sifatnya masih belum pasti kebenarannya. Didasari oleh penelitian yang akan di uji, maka sebagian jawaban sementara atau hipotesis statistik nya adalah sebagai berikut:

Pengujian pengaruh X kepada $\mathrm{Y}$. $\mathrm{H} 0: \beta \leq 0$

$\mathrm{H} 1: \beta>0$

Keterangan:

$\mathrm{H} 0=$ Hipotesis Nol

$\mathrm{H} 1=$ Hipotesis Alternatif

$\beta=$ Koefisien regresi yang menyatakan pengaruh Bauran Promosi (X) terhadap Kesadaran $\operatorname{Merek}(\mathrm{Y})$

\section{Uji Validitas}

Uji validitas instrumen menggunakan teknis analisis korelasi product moment pearson dan menggunakan bantuan SPSS. Uji signifikansi dilakukan dengan membandingkan nilai $r$ hitung dengan $r$ tabel. Menurut Sugiyono (Sugiyono, 2010, p. 109) "Uji validitas didapatkan dengan cara mengkorelasikan setiap skor dengan total skor indikator variabel kemudian hasil korelasinya dibandingkan dengan nilai kritis pada signifikan 0,05 " Syarat minimum instrumen penelitian dikatakan valid apabila nilai $r$ hitung $>r$ tabel.

\section{Uji Reliabilitas}

Nilai reliablitias variabel ditunjukkan oleh koefisien Cronbach Alpha yang pada program SPSS disebut dengan Reability Analysis. Maka dapat disimpulkan bahwa: 
a. Jika nilai Cronbach's Alpha > 0,6 maka instrumen penelitian dikatakan reliabel.

b. Jika nilai Cronbach's Alpha $<0,6$ maka instrumen penelitian dikatakan tidak reliabel.

Tabel 1. Interprestasi Koefisien Korelasi Realibilitas

\begin{tabular}{cc}
\hline Koefisien Rellibilitas & Interprestasi \\
\hline 0,900 & Reliabilitas Sangat Tinggi \\
\hline $0,80 \leq$ rxy $\leq 0,9$ & Reliabilitas Tinggi \\
\hline $0,70 \leq$ rxya $\leq 0,80$ & Reliabilitas Cukup \\
\hline $0,60 \leq$ rxya $\leq 0,70$ & Reliabilitas Rendah \\
\hline 0,60 & Reliabilitas Sangat Rendah \\
\hline
\end{tabular}

Tabel 2. Interval Koefisien Korelasi

\begin{tabular}{cc}
\hline Interval Koefisien & Tingkat Hubungan \\
\hline $0,80-1,000$ & Sangat Kuat \\
\hline $0,60-0,799$ & Kuat \\
\hline $0,40-0,599$ & Cukup Kuat \\
\hline $0,20-0,399$ & Rendah \\
\hline $0,00-0,199$ & Sangat Rendah \\
\hline
\end{tabular}

\section{Teknik Data Analisis Regresi Linear Sederhana}

Dalam penelitian ini akan menggunakan kajian regresi linier sederhana, di mana hanya dapat satu variabel independen yang akan dihubungkan dengan satu variabel dependen. Jika hubungan tersebut linear maka hubungan tersebut dapat dijabarkan sebagai berikut:

$$
\mathbf{Y}=\mathbf{a}+\mathbf{b X}
$$

Keterangan:

$\mathrm{X}=$ Bauran Promosi $\mathrm{Y}=$ Kesadaran Merek $\mathrm{a}=$ Konstanta $\mathrm{b}=$ Koefisien regresi

Tabel 3. Operasional Konsep

\begin{tabular}{|c|c|c|c|}
\hline & Dimensi & Indikator & Skala \\
\hline \multirow{3}{*}{$\begin{array}{c}\text { Bauran Promosi } \\
\text { (Promotion Mix) } \\
(\mathbf{x})\end{array}$} & $\begin{array}{l}\text { Periklanan } \\
\text { (Advertising) }\end{array}$ & $\begin{array}{l}\text { - Ketepatan periklanan melalui program media } \\
\text { - } \text { Daya tarik iklan melalui program media } \\
\text { - Kemudahan memahami isi pesan yang } \\
\text { disampaikan melalui program } \\
\text { - Ketepatan informasi } \\
\text { diberikan melalui media }\end{array}$ & \\
\hline & $\begin{array}{l}\text { Hubungan } \\
\text { Masyarakat } \\
\text { (Public Relations) }\end{array}$ & 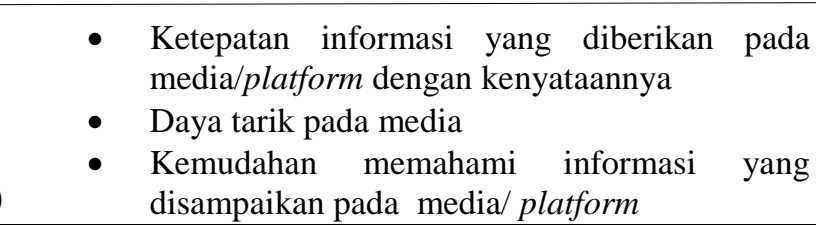 & Likert \\
\hline & Top of Mind & $\begin{array}{ll}\text { - } & \text { Tingkat ingatan terhadap merek } \\
\text { - } & \text { Tingkat intensitas merek muncul dalam benak }\end{array}$ & \\
\hline & Brand Recall & - $\quad$ Tingkat penyebutan kembali merek & \\
\hline
\end{tabular}




\begin{tabular}{cccl}
\cline { 2 - 4 } Kesadaran & Brand & $\bullet$ & Frekuensi mendengar \\
Merek (Brand & Recognition & $\bullet$ & Tingkat pengingatan kembali \\
\cline { 2 - 4 } Awareness) $(\mathbf{y})$ & & $\bullet$ & Tingkat ketidaksadaran hadirnya produk \\
& Unaware of & $\bullet$ & Tingkat Pengetahuan merek \\
& Brand & & \\
\end{tabular}

\section{HASIL DAN PEMBAHASAN}

\section{Hasil}

Penelitian ini dilakukan pada pengunjung website Pricebook, subscriber Pricebook, dan penonton Youtube Pricebook. Responden yang akan diteliti pada penelitian ini adalah sebanyak 97 orang. Dengan syarat responden yaitu berusia 18-35 tahun, telah menjadi subscriber/viewers Youtube Pricebook dan pengunjung website Pricebook. Hasil dari penelitian terhadap responden-responden ini terdapat pada tabel-tabel di bawah ini.

\section{Uji Validitas}

Tabel 5.

\begin{tabular}{lccll}
\hline Variabel & Indikator & r hitung & $\begin{array}{l}\text { r tabel } \\
(0,05)\end{array}$ & Keterangan \\
\hline Bauran Promosi (BP) & BP1 & 0,767 & 0,1996 & Valid \\
\cline { 2 - 5 } & BP2 & 0,797 & 0,1996 & Valid \\
\cline { 2 - 5 } & BP3 & 0,740 & 0,1996 & Valid \\
\cline { 2 - 5 } & BP4 & 0,652 & 0,1996 & Valid \\
\hline & BP5 & 0,779 & 0,1996 & Valid \\
\cline { 2 - 5 } & BP7 & 0,773 & 0,1996 & Valid \\
\hline \multirow{3}{*}{ Kesadaran Merek } & BP9 & 0,599 & 0,1996 & Valid \\
\cline { 2 - 5 } (KM) & BP10 & 0,794 & 0,1996 & Valid \\
\cline { 2 - 5 } & KM1a & 0,712 & 0,1996 & Valid \\
\cline { 2 - 5 } & KM1b & 0,659 & 0,1996 & Valid \\
\cline { 2 - 5 } & KM1c & 0,693 & 0,1996 & Valid \\
\cline { 2 - 5 } & KM2a & 0,699 & 0,1996 & Valid \\
\cline { 2 - 5 } & KM2b & 0,698 & 0,1996 & Valid \\
\cline { 2 - 5 } & KM3a & 0,689 & 0,1996 & Valid \\
\cline { 2 - 5 } & KM3b & 0,761 & 0,1996 & Valid \\
\cline { 2 - 5 } & KM4a & 0,533 & 0,1996 & Valid \\
\cline { 2 - 5 } & KM4b & 0,584 & 0,1996 & Valid \\
\cline { 2 - 5 } & KM4c & 0,670 & 0,1996 & Valid \\
\hline
\end{tabular}

Berdasarkan hasil olah data yang disajikan pada tabel di atas, dapat diketahui bahwa seluruh butir pernyataan yang mengukur variabel independen yaitu bauran promosi (promotion mix) yang terdiri dari periklanan dan hubungan masyarakat serta variabel dependen yaitu kesadaran merek (brand awareness) dinyatakan valid, karena seluruh butir pernyataan menghasilkan nilai $r_{\text {hitung }}>r_{\text {tabel }}($ di atas 0,1996$)$.

\section{Uji Reliabilitas}

Tabel 6. Bauran Promosi (BP) (X) Reliability Statistics

\begin{tabular}{cc}
\hline Cronbach's Alpha & N of Items \\
\hline, 847 & 10 \\
\hline
\end{tabular}




\section{Tabel 7. Kesadaran Merek (KM) (Y) Reliability Statistics

\begin{tabular}{ccc}
\hline Cronbach's Alpha & N of Items & \\
\hline, 880 & 10
\end{tabular}

Hasil pada tabel di atas menunjukkan bahwa pernyataan dalam kuesioner penelitian ini reliabel karena keseluruhan variabelnya yaitu X $(0,847)$ dan Y $(0,880)$ memiliki nilai Cronbach Alpha lebih besar dari 0,6. Hal ini mengindikasikan bahwa setiap item pernyataan untuk keseluruhan variabel akan mampu digunakan guna memperoleh data yang konsisten, artinya apabila pernyataan itu diajukan kembali maka akan diperoleh jawaban yang relatif sama.

\section{Uji Analisis Regresi Linear Sederhana}

Tabel 8.Model Summary

\begin{tabular}{|c|c|c|c|c|}
\hline Model & $\mathrm{R}$ & R Square & $\begin{array}{l}\text { Adjusted } \\
\text { Square }\end{array}$ & $\begin{array}{l}\text { RStd. Error of the } \\
\text { Estimate }\end{array}$ \\
\hline 1 & $.686^{\mathrm{a}}$ & .470 & .465 & 3.735 \\
\hline
\end{tabular}

\section{Hasil Analisis Koefisien Korelasi dan Koefisien Determinasi}

Berdasarkan tabel di atas, diketahui bahwa koefisien korelasi antara variable Bauran Promosi (Promotion Mix) dan Kesadaran Merek (Brand Awareness) adalah sebesar 0,686. Tabel di atas dibuat untuk mengetahui nilai hubungan antara variabel independen, yaitu Bauran Promosi (Promotion Mix) dengan variabel dependen, yaitu Kesadaran Merek (Brand Awareness). Adapun koefisien korelasi antara kedua variabel tersebut adalah 0,686. Ini menunjukan bahwa Bauran Promosi (Promotion Mix) terhadap Kesadaran Merek (Brand Awareness) memiliki hubungan yang kuat karena berada diantara 0,60-0,799. Sedangkan koefisien determinasi adalah sebesar 0,470 yang berarti sebesar $47 \%$ variabel Bauran Promosi (Promotion Mix) mempengaruhi Kesadaran Merek (Brand Awareness) sedangkan sisanya sebesar 53\% dipengaruhi oleh faktor-faktor lainnya. Hasil akhir dari penelitian ini adalah Bauran Promosi (Promotion Mix) terbukti mempunyai pengaruh sebesar $47 \%$ terhadap Kesadaran Merek (Brand Awareness).

Tabel 9.Coefficients

\begin{tabular}{|c|c|c|c|c|c|c|}
\hline & & & & $\begin{array}{l}\text { Standardized } \\
\text { Coefficients }\end{array}$ & & \\
\hline & & Uns & ed Coeffici & & & \\
\hline & Model & $\mathrm{B}$ & Std. Error & Beta & $\mathrm{t}$ & Sig. \\
\hline 1 & (Constant) & 9.075 & 3.195 & & 2.840 & .006 \\
\hline & total $\mathrm{x}$ & .739 & .080 & .686 & 9.183 & .000 \\
\hline
\end{tabular}

Berdasarkan tabel di atas, didapatkan persamaan regresi linear sederhana yang melalui rumus: $Y=a+b X$ Di mana:

$\mathrm{X}=$ Bauran Promosi $\mathrm{Y}=$ Kesadaran Merek $\mathrm{a}=$ Konstanta

$\mathrm{b}=$ Koefisien regresi

Oleh karena itu, mengacu pada rumus tersebut, maka terdapat persamaan linear sederhana: $\mathrm{Y}=9,075+0,739 \mathrm{X}$ 


\section{PROPAGANDA}

\section{Pembahasan}

Hasil perhitungan analisis tersebut, terdapat pernyataan bahwa nilai a (konstanta) pada tabel unstandarized coefficients adalah sebesar 9,075 yang berarti bahwa jika tidak ada variabel independen, maka variabel Kesadaran Merek memiliki nilai 9,075, dan apabila nilai variabel Bauran Promosi sama dengan satu maka nilai koefisien regresi variabel Kesadaran Merek sebesar 0,739. Dengan tingkat signifikan sebesar 0,000 dan dikarenakan 0,000 < 0,05 maka dapat dikatakan Bauran Promosi (Variabel X) sangat berpengaruh terhadap Kesadaran Merek (Variabel Y) pada $\alpha=5 \%$. Menurut teori yang digunakan di dalam penelitian ini, adanya pengaruh yang signifikan antara Bauran Promosi (X) terhadap Kesadaran Merek (Y), dengan kata lain Bauran Promosi (X) memiliki pengaruh terhadap Kesadaran Merek (Y) menurut data dari pengunjung website atau penonton channel YouTube Pricebook. Berdasarkan hasil dari penelitian yang telah dilakukan terhadap pengunjung website dan penonton YouTube Pricebook, dapat diketahui bahwa pengaruh dari Bauran Promosi terhadap Kesadaran Merek kuat dan signifikan serta berpengaruh positif. Hal ini dapat dilihat dari Uji Analisis Regresi Linear Sederhana yang telah dilakukan pada penelitian ini. Data dari responden kuesioner juga sudah dinyatakan valid dan reliabel.

\section{PENUTUP}

Berdasarkan penelitian yang telah dilakukan, Dengan uji validitas dan uji reliabilitas dapat diketahui bahwa data survei kuesioner dari 97 responden valid dan reliabel, serta menurut perhitungan uji analisis regresi linear sederhana, dapat diketahui bahwa Bauran Promosi (Promotion Mix) (X) berpengaruh secara signifikan dengan nilai 0,739>0,05 terhadap Kesadaran Merek (Brand Awareness) (Y). Dari uji tersebut juga dapat diketahui bahwa Bauran Promosi (Promotion Mix) (X) memiliki pengaruh positif sebanyak 47\% terhadap (Brand Awareness) (Y). Dari hasil penelitian ini, dapat diambil kesimpulan bahwa Bauran Promosi (Promotion Mix) (X) memiliki pengaruh yang kuat dengan korelasi 0,686 terhadap (Brand Awareness) (Y). Saran dari peneliti untuk perusahaan maupun pihak lain adalah untuk terus melakukan dan mengembangkan kegiatan-kegiatan periklanan maupun menjaga baik hubungan masyarakat untuk meningkatkan kesadaran merek yang dapat memberikan pengaruh yang baik atau positif terhadap Pricebook.

\section{DAFTAR PUSTAKA}

Ardianto; Soemirat. (2012). Dasar- dasar Public Relations. PT. Remaja Rosda Karya. Armstrong, G. M.; et. a. (2014). Principles of Marketing (6th ed.). Pearson.

Broom, Glen M.; Cutlip, Scott M.; Center, A. H. (2010). Effective Public Relations (8th ed.). PT. Indeks Kelompok Gramedia.

Buchari, A. (2014). Manajemen Pemasaran dan Pemasaran Jasa. Alfabeta.

Djasmin, S. (2012). Manajemen Pemasaran (3rd ed.). Linda Karya.

Durianto, Darmadi; Sugiarto; Sitinjak, T. (2011). Strategi Menaklukkan Pasar Melalui Riset Ekuitas dan Perilaku Merek. PT. Gramedia Pustaka Utama.

Ghozali, I. (2016). Aplikasi Analisis Multivariete Dengan Program IBM SPSS 23 (8th ed.). Badan Penerbit Universitas Diponegoro.

Johnson, Eugene M; Kurtz, David L; Scheuing, E. E. (2017). Sales Management : Consepts, Practices, and Cases (2nd ed.). McGraw-Hill. 
Kotler, P. (2012). Marketing Management (The Millen). Prentice Hall.

Lupiyoadi, R. (2013). Manajemen Pemasaran Jasa Berbasis Kompetensi (3rd ed.). Salemba Empat.

Purwanto. (2011). Evaluasi Hasil Belajar. Pustaka Belajar.

Raja, H. (2011). Analisis Pengaruh BauranPromosi Terhadap Kesadaran Merek (Brand

Awareness) Tabungan Britama PT. BRI (PERSERO) TBK. Kantor Cabang di Tebing Tinggi Ekonomi, Bisnis Dan Entrepreneurship, 11(01).

Sasmita, Jumiati; Suki, N. M. (2015). Young Consumers' Insights On Brand Equity: Effects Of Brand Association, Brand Loyalty, Brand Awareness, and Brand Image.

Journal of Retail \& Distribution Management, 43(3), 276-292. https://doi.org/10.1108/IJRDM- 02-2014-0024

Shimp, T. A. (2014). Komunikasi Pemasaran Terpadu dalam periklanan dan Promosi.

Salemba Empat.

Siregar, D. et. a. (2020). Technopreneurship: Strategi dan Inovasi. Yayasan Kita Menulis.

Sugiyono. (2010). Statistika Untuk Penelitian. Alfabeta.

Sugiyono. (2017). Metode Penelitian Kuantitatif, Kualitatif, dan R\&D. Alfabeta.

Sulistio, A. (2018). Pengaruh Promotion Mix Terhadap Brand Awareness PT HM Sampoerna TBK Melalui Produk Terbaru Sampoerna A Platinum. Jurnal Strategi Pemasaran, 5(2). http://publication.petra.ac.id/inde x.php/manajemenpemasaran/article/view/7308/662 4

Swastha; Irawan. (2016). Manajemen Pemasaran Modern. Liberty.

Tjiptono, F. (2015). Strategi Pemasaran (II). ANDI.

Umar, H. (2011). Riset Pemasaran dan Perilaku Konsumen. Gramedia Pustaka Utama.

Wells, William; Burnett, John; Moriarty, S. E. (2012). Advertising Principles and Practice (6th ed.). Prentice Hall 